\title{
Control Characteristics Improvement of Full-Bridge DC-DC Converter with Snubber Capacitor
}

\author{
Kazuhide Domoto, Yoichi Ishizuka \\ Graduate School of Engineering, Nagasaki University \\ 1-14 Bunkyo-machi, Nagasaki, Japan 852-8521
}

\begin{abstract}
A high-voltage full bridge dc-dc converter has a big problem of high-voltage surge occurrence across secondary-side rectifying diodes. In order to solve this problem, a simple solution with a snubber capacitor has been proposed. This technique provides a prominent effect of surge-voltage suppression. On the other hand, it deteriorates the control characteristics of this converter. In this paper, the control characteristics are analyzed by the state-space averaging method. Based on this analytical result, the improvement of the control characteristics is proposed. Some experiments confirm the effectiveness of the proposed technique.
\end{abstract}

Keywords-Full-Bridge DC-DC Converter, Surge Voltage, Snubber Capacitor, Control Characeristics

\section{INTRODUCTION}

Recently, the rapid growth of internet traffic has increased the number of ICT equipments in data center. Therefore, the electric power consumption in data center has been increased. The energy saving techniques are required in date center.

The conventional data center utilizes the power distribution system based on the combined power lines of $\mathrm{AC}$ and 48VDC. In case of AC system, the number of conversion stages is larger, and then its efficiency is lower. In case of $48 \mathrm{~V}$ DC system, the efficiency is higher due to smaller number of conversion stage. However, heavy current requires thicker power cables, and then flexibility of installation is limited.

In order to solve these difficulties, the power distribution system using High-Voltage Direct-Current (HVDC) e.g., 400V has been recently researched[1 2]. This HVDC system has several advantages such as higher efficiency due to smaller number of conversion stages, and easier installation due to finer power cables. In this system, a semiconductor circuit breaker and a high power-density isolated DC-DC converter are strongly demanded.

A full-bridge converter is considered as the isolated DC-DC converter. This full-bridge converter has some problems such that a large surge voltage occurs across the secondary side rectifying diodes[3].

\author{
Seiya Abe, Tamotsu Ninomiya \\ International Centre for the Study of East Asian \\ Development \\ 1-8 Hibikino, Wakamatsu-ku, Kitakyushu, Japan 808-0135
}

In the conventional lower-output-voltage converters, RC snubber circuits were usually used[4 7]. However, in higher-output-voltage converters, power loss at snubber resister becomes much larger, and then this method is impractical. Thus, another surge snubber is needed. Recently, a simple surge snubber using a capacitor only has been proposed in the previous papers[8 9], and its prominent effect on the surge suppression has been confirmed experimentally.

However, this snubber capacitor severally deteriorates the control characteristics of the converter.

In order to solve the above problem, this paper proposes a new technique of utilizing the transformer leakage inductance. The control characteristics of the Full-Bridge Converter with Snubber Capacitor (FB-SC) are analyzed, and the effect of the leakage inductance on the control characteristics improvement is experimentally confirmed.

\section{FULL-BRIDGE DC-DC CONVERTER WITH SNUBBER CAPACITOR}

A block diagram of the HVDC power distribution system is shown in Fig. 1. The first stage consists of a power-factor-correction (PFC) converter for the harmonic reduction of input current waveform. The subsequent DC-DC converter operates for the dc-isolation and the voltage regulation. A circuit topology of the FB-SC is shown in Fig. 2, where the output-voltage regulation is performed by the phase-shift driving.

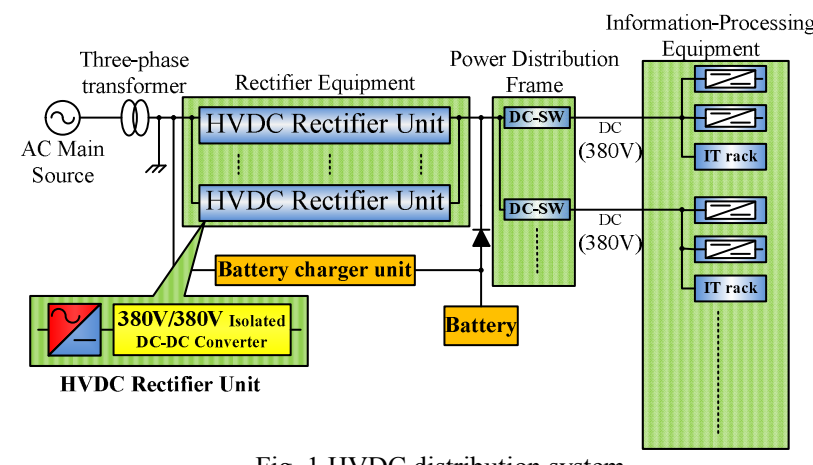

Fig. 1 HVDC distribution system 
The surge suppression effect of this topology has been confirmed in reference. However, this snubber capacitor severally deteriorates the control characteristics of the converter. In ideal case, the output voltage can be derived as following equation;

$$
V_{\mathrm{CS}}=\frac{V_{\text {in }}}{n}=V_{O}
$$

From Eq. (1), the output voltage is decided by snubber capacitor voltage $\mathrm{V}_{\mathrm{CS}}$, and the output voltage cannot be controlled by the phase-shift driving.

In order to control the output voltage, the output voltage variation has been experimentally confirmed by the influence of leakage inductance so far[10].

Here, the effect of the leakage inductance on the control characteristics improvement is investigated. The relationship between the leakage inductance and the control characteristics are analyzed in next chapter.

\section{ANALYTICAL RESULTS}

Figure 3 shows the key waveforms of the FB-SC. From these waveforms, the operating states can be divided into 7 states in a half switching cycle. Figure 4 shows the each operating state of this circuit.

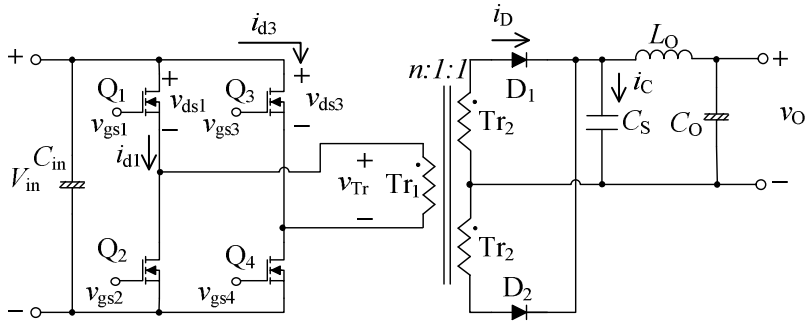

Fig. 2 Full-bridge DC-DC converter with snubber capacitor

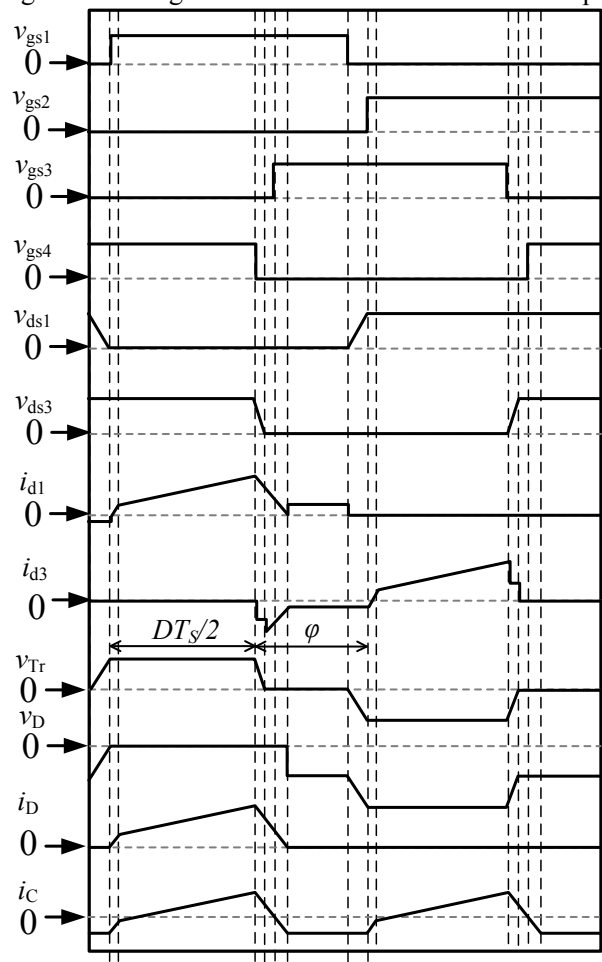$$
\text { 1) }
$$

\begin{tabular}{l|l|l|l|l|l|l|} 
State 1 & State 2 & State 3 & State 4 & State 5 & State 6 & State 7
\end{tabular}

Fig. 3 Key waveforms

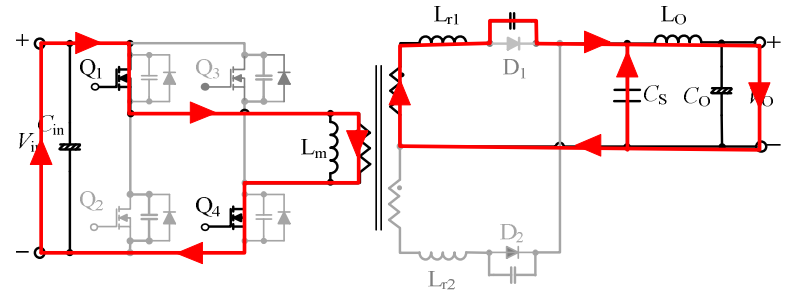

(a) State 1

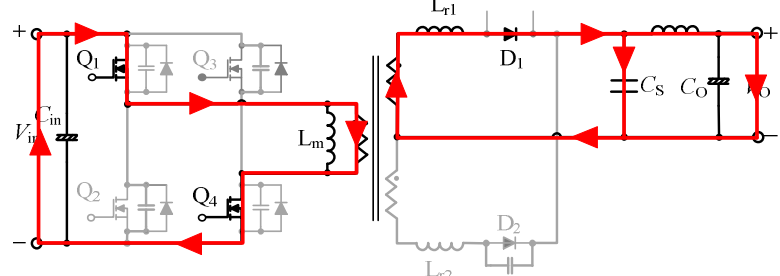

(b) State 2

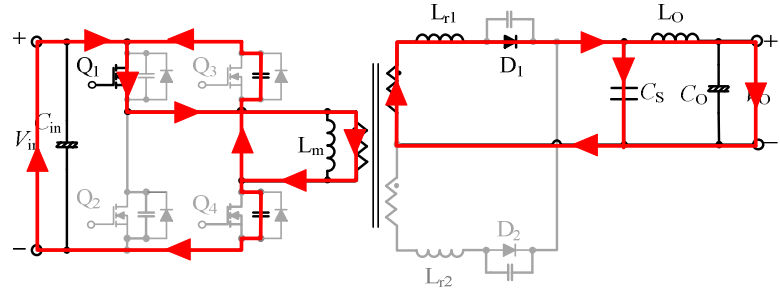

(c) State 3

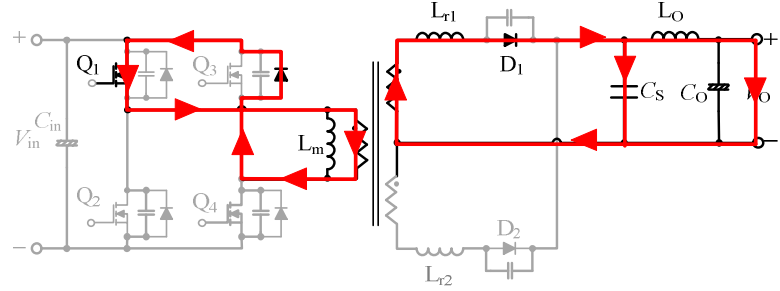

(d) State 4

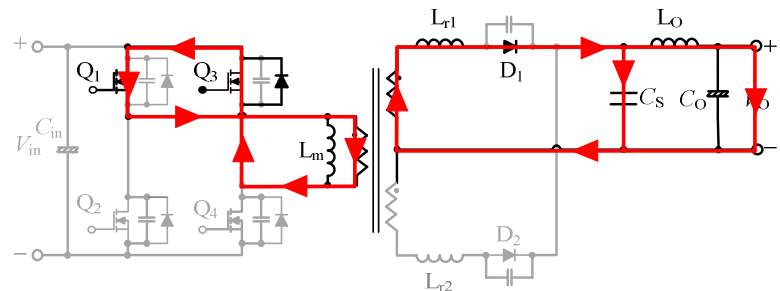

(e) State 5

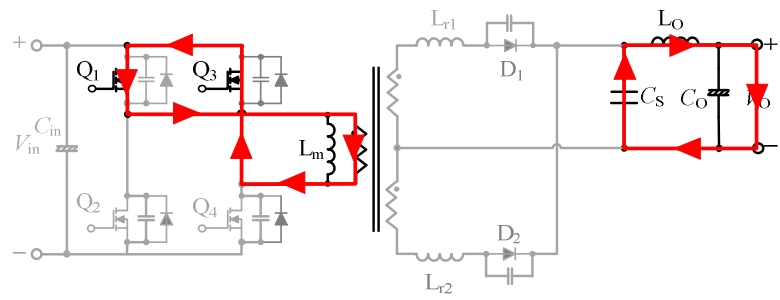

(f) State 6

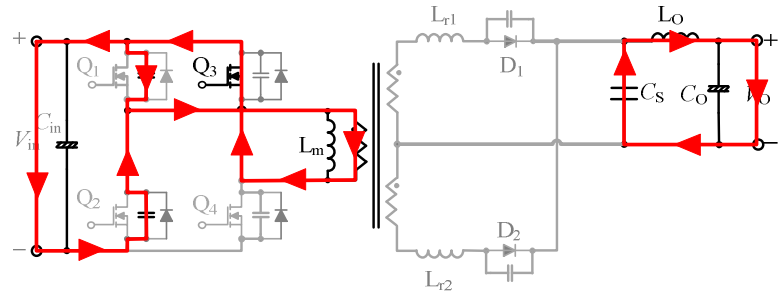

(g) State 7

Fig. 4 Operating states 
The property of the circuit operations are shown as follows;

State 1: This state begins when Switch $Q_{1}$ turned on. During this period, the electric charge of secondary side diode's junction capacitance is discharged to output side. This state will be continued until the electric charge reaches zero.

State 2: Diode $D_{1}$ is turned on, and the power is transferred from primary side to the load. During this period, the applied voltage across the transformer is equal to input voltage $V_{\text {in }}$, and the energy of leakage inductance is stored by the secondary side current. This state will be end when the switch $\mathrm{Q}_{4}$ turns off.

State 3: The current flowing through the switch $\mathrm{Q}_{3}$ discharges parasitic capacitor. At that same time, the current flowing through the switch $\mathrm{Q}_{4}$ charges parasitic capacitor. The energy stored in the leakage inductance is transferred to the load. This state will be end when the voltage $V_{\mathrm{ds} 1}$ reaches zero and the voltage $V_{\mathrm{ds} 4}$ reaches input voltage.

State 4: The body diode of switch $\mathrm{Q}_{3}$ is turned on by the stored energy of the leakage inductance.

State 5: This state begins the switch $\mathrm{Q}_{3}$ turns on under the ZVS condition. During this period, the current flowing through the switch $\mathrm{Q}_{3}$ is negative because of the stored energy of the leakage inductance. This state will be end when the secondary side diode current reaches zero (stored energy of leakage inductance reaches zero).

State 6: During this period, the primary side current is circulating through switch $\mathrm{Q}_{1}$ and $\mathrm{Q}_{3}$. The secondary side rectifying diode $\mathrm{D}_{1}$ is turned off. The output power is provided from snubber capacitor. This state will be end when the switch $\mathrm{Q}_{1}$ turns off.

State 7: This state begins the switch $\mathrm{Q}_{1}$ turns off. The current flowing through the switch $\mathrm{Q}_{2}$ discharges parasitic capacitor. At that same time, the current flowing through the switch $\mathrm{Q}_{1}$ charges parasitic capacitor. This state will be end when the voltage $V_{\mathrm{ds} 2}$ reaches zero and the voltage $V_{\mathrm{ds} 1}$ reaches input voltage.

The voltage conversion ratio can be derived by means of the extended state-space averaging method[11]. In order to simplify the state analysis, the primary side is modeled to the just voltage source, and then the parameters are converted to the secondary side. Based on this, the analytical models can be divided into 4 states by the considering of secondary side states as shown in Fig. 5. Where, the state 1 can be neglected because of very short interval. However, the state 1 is needed to calculate initial value. From these equivalent circuits, the state equations are derived as follows;

$$
\left\{\begin{aligned}
\frac{d \hat{v}_{\mathrm{S}}}{d t}= & -\frac{D^{2} T_{\mathrm{S}} V_{\mathrm{in}} / n}{4 C_{S} L_{\mathrm{r} 1}}+\frac{D^{2} T_{\mathrm{S}} V_{\mathrm{in}}^{2} / n^{2}}{4 C_{S} L_{\mathrm{r} 1} \hat{v}_{\mathrm{S}}} \\
& +\frac{L_{\mathrm{r} 1}}{C_{S} T_{\mathrm{S}} \hat{v}_{\mathrm{S}}} I_{\mathrm{D} 0}^{2}+\frac{D V_{\mathrm{in}} / n}{C_{S} \hat{v}_{\mathrm{S}}} I_{D 0}-\frac{\hat{i}_{\mathrm{L}}}{C_{S}} \\
\frac{d \hat{i}_{\mathrm{L}}}{d t}= & \frac{-r_{\mathrm{L}} \hat{i}_{\mathrm{L}}+\hat{v}_{\mathrm{S}}-\hat{v}_{\mathrm{O}}}{L_{\mathrm{O}}} \\
\frac{d \hat{v}_{\mathrm{O}}}{d t}= & \frac{\hat{i}_{\mathrm{L}}-I_{\mathrm{O}}}{C_{\mathrm{O}}}
\end{aligned}\right.
$$

Where, the duty ratio $\mathrm{D}$ has been defined by means of $\varphi$ which is the phase difference between switch $\mathrm{Q}_{1}$ and $\mathrm{Q}_{4}$ as following equation;

$$
D=1-\frac{\varphi}{180}
$$

Moreover, $I_{\mathrm{D} 0}$ is the initial value of the diode current. In the steady state, the left side of Eq. (2) is equal to zero. Thus, the output voltage is derived as follows;

$$
V_{\mathrm{O}}=\frac{V_{i n}}{n}+\frac{\frac{I_{D 0}^{2} L_{\mathrm{r} 1}}{T_{\mathrm{S}} I_{\mathrm{O}}}-\frac{V_{i n}}{n}\left(1-D \frac{I_{D 0}}{I_{\mathrm{O}}}\right)}{1+\frac{D^{2} T_{\mathrm{S}} V_{\mathrm{in}}}{4 n L_{\mathrm{r} 1} I_{\mathrm{O}}}}-r_{\mathrm{L}} I_{\mathrm{O}}
$$

In order to evaluate Eq. (4), the estimation of initial value is required.

\section{A. Initial value $I_{D 0}$}

The initial value is equal to the diode current at the end of state 1 . Estimating the initial value $I_{\mathrm{D} 0}$, the transient analysis of state 1 is necessary. The equivalent circuit of state 1 is shown in Fig. 5(a). From this equivalent circuit, the diode current $i_{\mathrm{D}}$ can be derived from following equations.

$$
i_{D}(t)=\frac{V_{i n}}{n} \sqrt{\frac{C_{d}}{L_{r 1}}} \sin \frac{t}{\sqrt{C_{d} L_{r 1}}}
$$

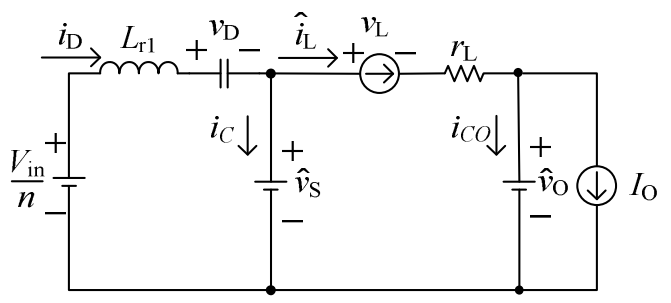

(a) State. 1

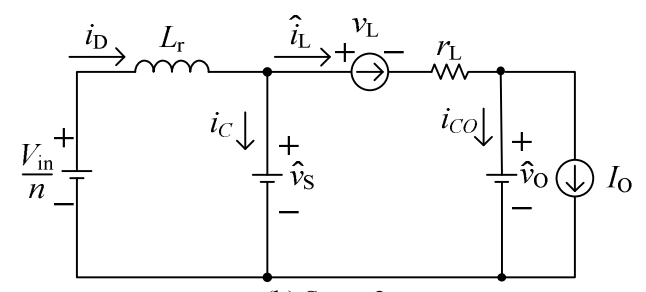

(b) State. 2

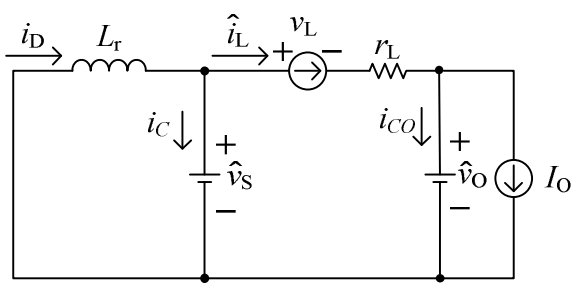

(c) State. 3 to 5

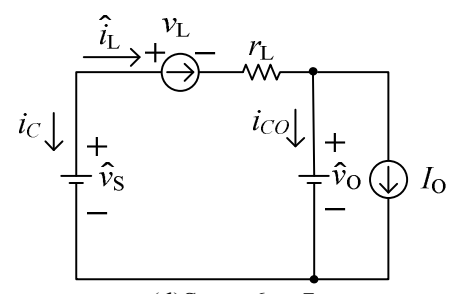

(d)State. 6 to 7

Fig. 5 Analyzed model 
Further, the diode voltage $v_{\mathrm{D}}$ is derived as follows:

$$
v_{D}(t)=\frac{V_{i n}}{n}\left(1-\cos \frac{t}{\sqrt{C_{d} L_{r 1}}}\right)-V_{O}
$$

When the diode voltage reaches zero, the diode current is equal to initial value $i_{\mathrm{D} 0}$.

From Eq. (5) and (6), the initial value $I_{\mathrm{D} 0}$ is derived as follows;

$$
I_{D 0}=\frac{V_{i n}}{n} \sqrt{\frac{C_{d}}{L_{r 1}}\left\{1-\left(1-n \frac{V_{O}}{V_{i n}}\right)^{2}\right\}}
$$

The initial value depends on the output voltage as shown in Eq. (7). Therefore, the initial value is increasing with increasing the output voltage. When the output voltage is equal to the input voltage, the initial value becomes maximum value as shown in Eq. (8).

$$
I_{D 0}=\frac{V_{i n}}{n} \sqrt{\frac{C_{d}}{L_{r 1}}}
$$

From Eq. (4) and (7), the output voltage is obtained. Further, the output voltage approximately expressed by neglecting the infinitesimal terms as follows;

$$
V_{\mathrm{O}}=\frac{V_{i n}}{n}\left(1-\frac{1-\frac{D V_{i n}}{n I_{\mathrm{O}}} \sqrt{\frac{C_{d}}{L_{r 1}}\left\{1-\left(1-n \frac{V_{O}}{V_{i n}}\right)^{2}\right\}}}{1+\frac{D^{2} T_{\mathrm{S}} V_{\mathrm{in}}}{4 L_{\mathrm{r} 1} I_{\mathrm{O}}}}\right)
$$

From Eq. (9), the output voltage depends on the leakage inductance. The control characteristics may be improved by means of the leakage inductance.

\section{B. The control characteristics of FB-SC}

The circuit parameters and specifications are shown in Table. I. The voltage difference between input and output voltage becomes small in this case as shown in Table. I. When voltage difference is smaller, the initial value reaches maximum value of the $I_{\mathrm{D} 0}$ as shown Eq. (8). Therefore, the maximum value of $I_{\mathrm{D} 0}$ utilizes as the initial value. In this case, the output voltage becomes as follows in approximately;

\begin{tabular}{|c|c|c|c|}
\hline \multicolumn{2}{|c|}{ Description } & \multicolumn{2}{|c|}{ Value } \\
\hline \multicolumn{2}{|c|}{ Input Voltage } & \multicolumn{2}{|c|}{$340 \mathrm{~V}$ to $420 \mathrm{~V}$} \\
\hline \multicolumn{2}{|c|}{ Output Voltage } & \multicolumn{2}{|c|}{$380 \mathrm{~V}$} \\
\hline \multicolumn{2}{|c|}{ Load Current } & \multicolumn{2}{|c|}{$0.2 \mathrm{~A}$ to $2.5 \mathrm{~A}$} \\
\hline \multicolumn{2}{|c|}{ MOSFET } & SPP20N60S5 & $650 \mathrm{~V} / 20 \mathrm{~A}$ \\
\hline \multicolumn{2}{|c|}{ Diode } & C2D10120 & $1200 \mathrm{~V} / 10 \mathrm{~A}$ \\
\hline \multirow{3}{*}{ Transformer } & $\mathrm{L}_{\mathrm{m}}$ & \multicolumn{2}{|c|}{$450 \mu \mathrm{H}$} \\
\hline & $\mathrm{L}_{\mathrm{r}}$ & \multicolumn{2}{|c|}{$2 \mu \mathrm{H}$} \\
\hline & Turn ratio & \multicolumn{2}{|c|}{$28: 30: 30$} \\
\hline \multicolumn{2}{|c|}{ Snubber Capacitor } & \multicolumn{2}{|c|}{$330 \mathrm{nF}$} \\
\hline \multicolumn{2}{|c|}{ Output indutor } & \multicolumn{2}{|c|}{$300 \mu \mathrm{H}$} \\
\hline \multicolumn{2}{|c|}{ Smoothing capacitor } & \multicolumn{2}{|c|}{$47 \mu \mathrm{F}$} \\
\hline \multicolumn{2}{|c|}{ Switching frequency } & \multicolumn{2}{|c|}{$200 \mathrm{kHz}$} \\
\hline
\end{tabular}

$$
V_{\mathrm{O}}=\frac{V_{i n}}{n}\left(1-\frac{1-\frac{D V_{i n}}{n I_{\mathrm{O}}} \sqrt{\frac{C_{d}}{L_{r 1}}}}{1+\frac{D^{2} T_{\mathrm{S}} V_{\mathrm{in}}}{4 L_{\mathrm{r} 1} I_{\mathrm{O}}}}\right)
$$

TABLE I The circuit parameters and specification
Figure. 6 shows the output voltage characteristics against the duty ratio. The output voltage variation becomes larger with large leakage inductance and its variation becomes smaller with large duty ratio. Moreover, the voltage variation becomes small when the leakage inductance is smaller. When the leakage inductance is $1 \mu \mathrm{H}$, the output voltage is not able to be controlled by the duty ratio independently on load condition as shown in Fig. 6.

Furthermore, the output voltage variation depends on the load current. When the load current is lower, the output voltage variation becomes small. Therefore, the large leakage inductance is needed to obtain the wide control range in light load case.

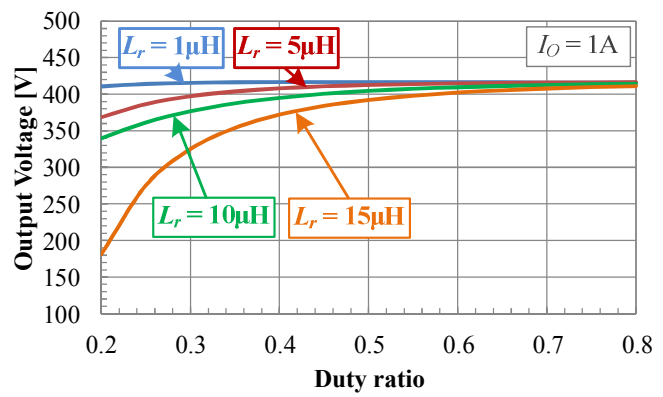

(a) $I_{\mathrm{O}}=1 \mathrm{~A}$

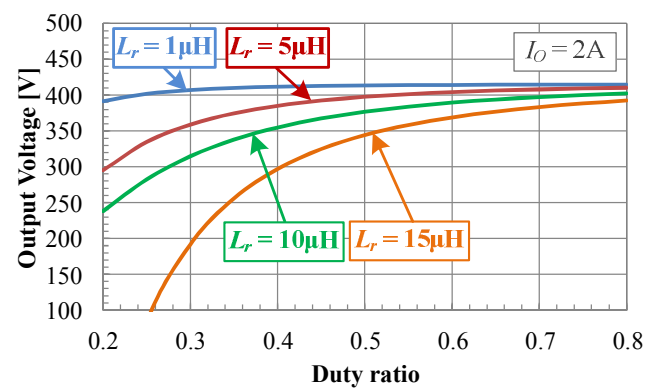

(b) $I_{\mathrm{O}}=2 \mathrm{~A}$

Fig. 6 Control characteristics

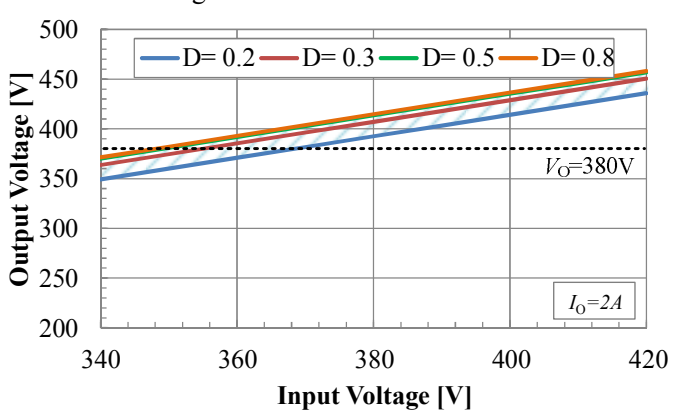

(a) leakage inductance $1 \mu \mathrm{H}$

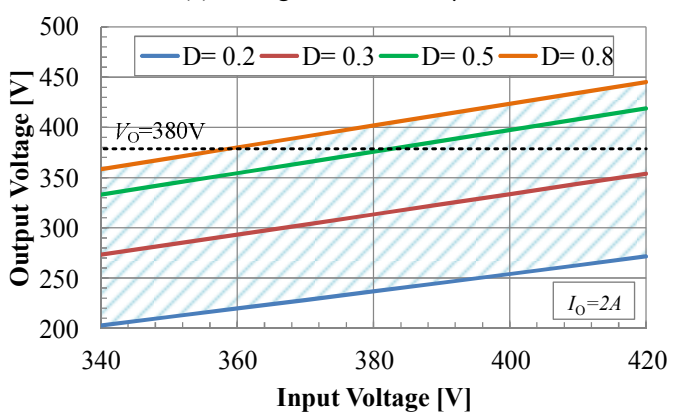

(b) leakage inductance $10 \mu \mathrm{H}$

Fig. 7 Line characteristics 
Figure 7 shows the relationship between the input and output voltage. The output voltage is almost linearly dependent on the input voltage. In the case of the small leakage inductance, the output voltage variation width by the duty ratio becomes narrow as shown in Fig. 7(a). On the other hand, when the leakage inductance is larger, the output voltage variation width by the duty ratio becomes wider as shown in Fig. 7(b).

Figure 8 shows the load characteristics with various duty ratio. In the case of the small leakage inductance, the output voltage independent on the duty ratio as shown in Fig. 8 (a). When the leakage inductance is lager, the control range of the output voltage becomes wider.

From the these analytical results, it is clarified that the control characteristics is improved by larger leakage inductance.

\section{EXPERIMENTAL RESULTS}

In order to examine the validity of the analytical results, the experimental measurements are necessary. The prototype evaluation board has been implemented, and the circuit parameters and specifications are utilized the same as the analytical works as shown in Table I. Here, the external inductances are installed in secondary side instead of leakage inductance.

Figure 9 shows experimental key waveforms. A little ringing is confirmed. However, the experimental key waveforms agree with theoretical key waveforms.

Figure 10 shows the output voltage characteristics against the duty ratio. When the leakage inductance is $2 \mu \mathrm{H}$, the output voltage cannot be controlled by the duty ratio as shown Fig. 10(a). On the other hand, the output voltage can be controlled by the duty ratio when the leakage inductance is $12 \mu \mathrm{H}$ as shown Fig. 10(b).

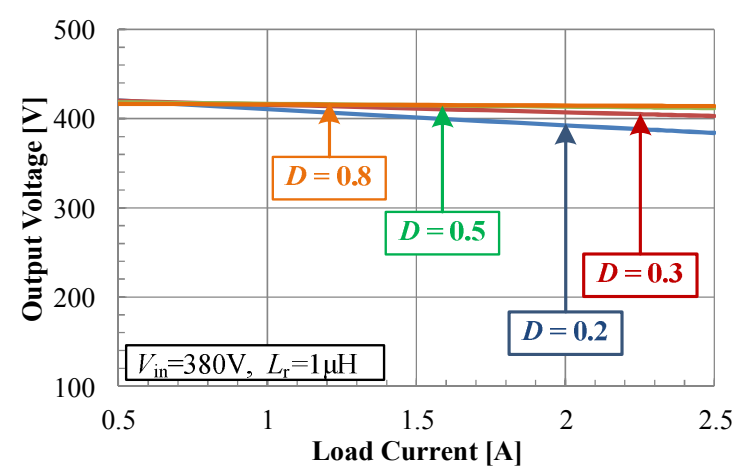

(a) leakage inductance $1 \mu \mathrm{H}$

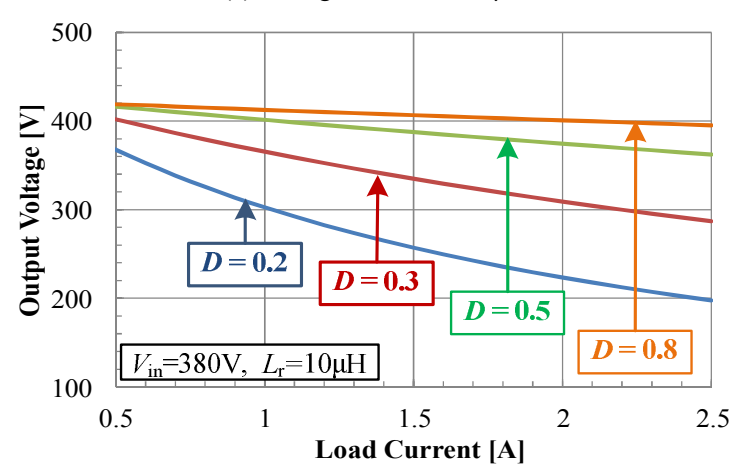

(a) leakage inductance $10 \mu \mathrm{H}$

Fig. 8 Load characteristics
The output voltage can be controlled by the duty ratio between 0.2 and 0.4 when the load current is $1 \mathrm{~A}$ as shown in Fig. 10 (a). On the other hand, when the load current is $2 \mathrm{~A}$, the output voltage can be controlled by the duty ratio between 0.2 and 0.6 as shown in Fig. 10 (b). From these results, it is clarified that the control range depends on not only leakage inductance but also load current. Therefore, the design of this converter is necessary to consider the above dependence.

Figure 12 shows the relationship between the input and output voltage. The output voltage is almost linearly dependent on the input voltage. When the leakage inductance is $2 \mu \mathrm{H}$, the output voltage is not able to control as shown in Fig. 11(a). On the other hand, when the leakage inductance is $10 \mu \mathrm{H}$, the output voltage can be controlled as shown in Fig. 11(b).
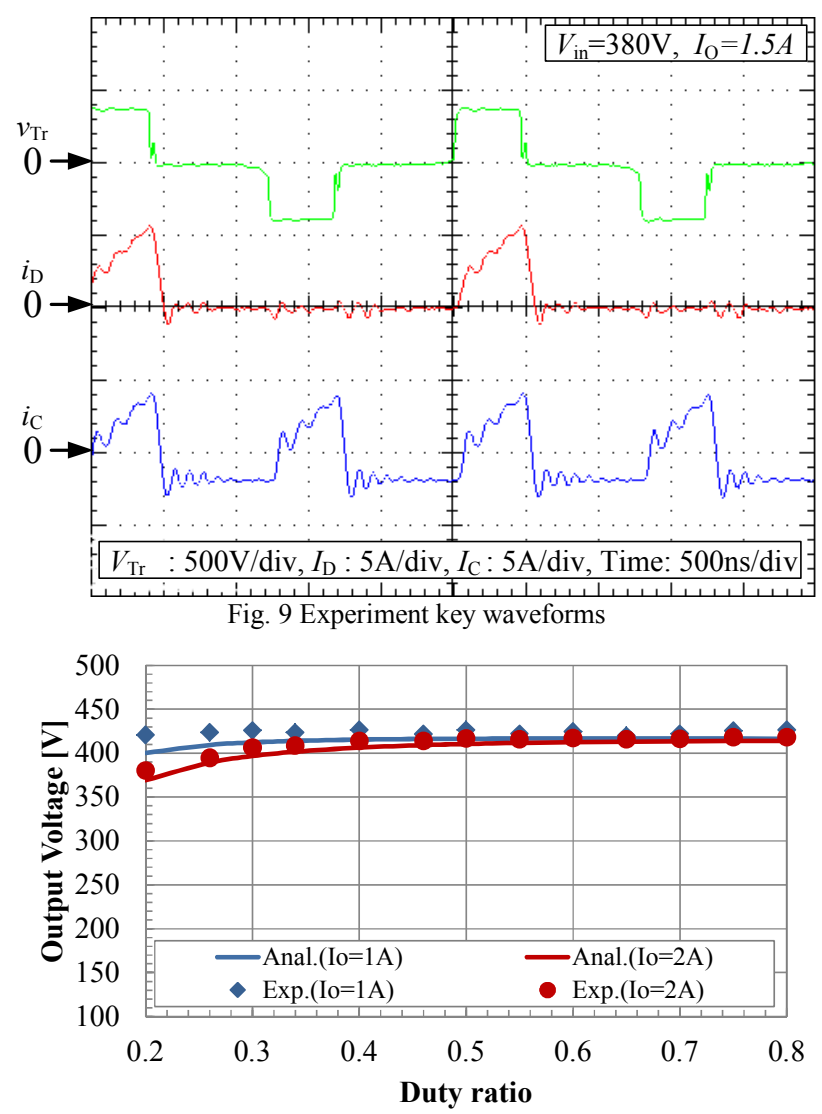

(a) leakage inductance $2 \mu \mathrm{H}$

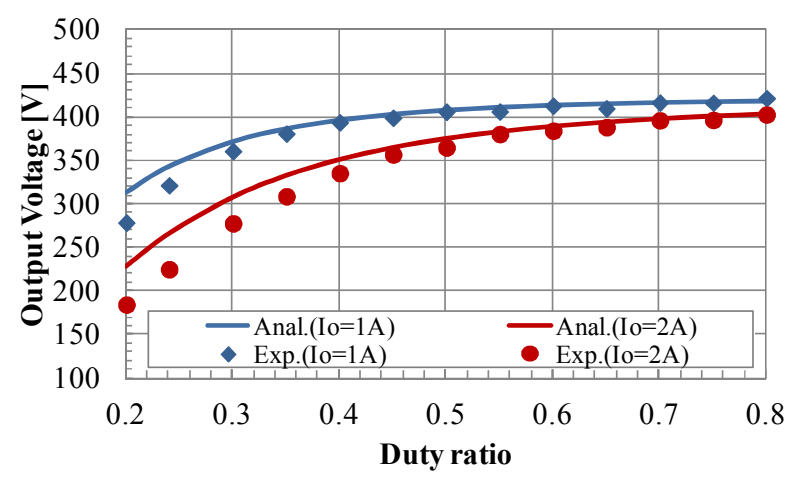

(b) leakage inductance $12 \mu \mathrm{H}$

Fig. 10 Control characteristics 
Figure 12 shows the load characteristics with various duty ratio. The output voltage decreases with decreasing the load current. The output voltage variation is changed depending on the leakage inductance. When the leakage inductance is $2 \mu \mathrm{H}$, the output voltage independent on the duty ratio as shown in Fig. 12 (a). When the leakage inductance is $12 \mu \mathrm{H}$, the control range of the output voltage becomes wider as shown in Fig. 12 (b).

These experimental results are agreed well analytical results. Moreover, the control characteristics improvement by mean of leakage inductance is confirmed by analytical and experimental.

\section{CONCLUSIONS}

This paper proposed a new technique of utilizing the transformer leakage inductance in order to improve the control characteristics of the Full-Bridge DC-DC converter with snubber capacitor. The effect of the leakage inductance on the control characteristics was clarified by analytical and experimental. As a result, it was confirmed that control range depends on not only leakage inductance but also load current. The design of leakage inductance for wide control range is necessary to consider the load condition.

The design technique of the leakage inductance will be discussed in the future work.

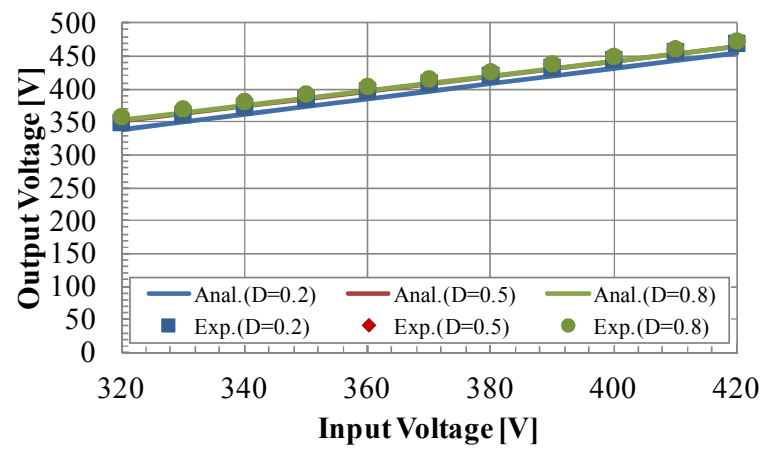

(a) leakage inductance $2 \mu \mathrm{H}$

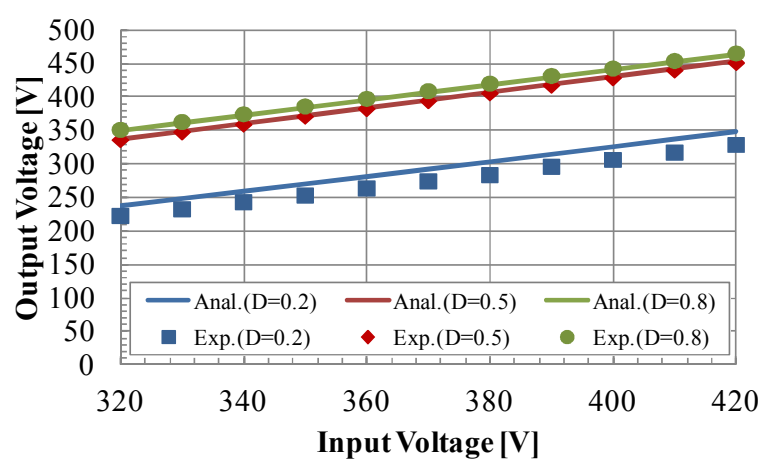

(b) leakage inductance $12 \mu \mathrm{H}$

Fig. 11 Line characteristics

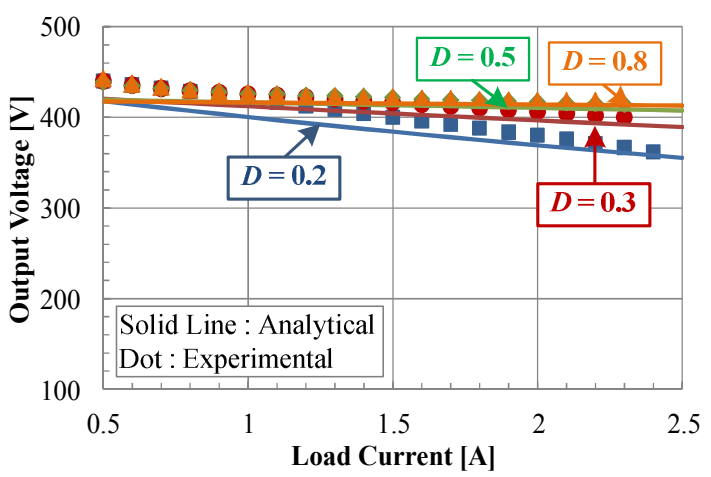

(a) leakage inductance $2 \mu \mathrm{H}$

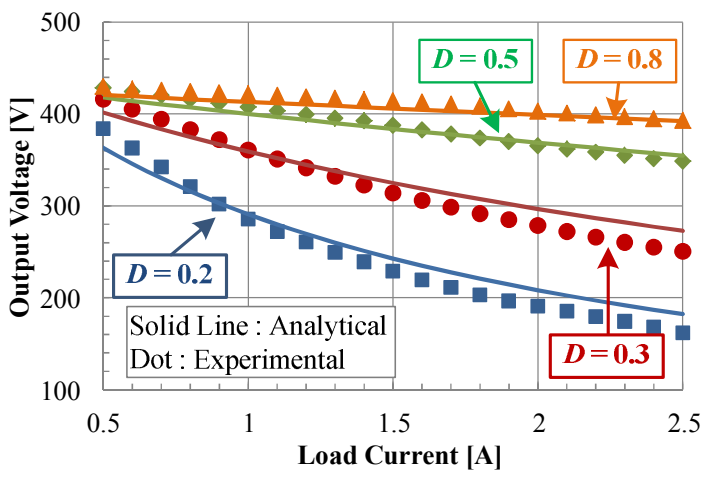

(b) leakage inductance $12 \mu \mathrm{H}$

Fig. 12 Load characteristics

\section{REFERENCES}

[1] A.Matsumoto, A.Fukui, T.Takeda, M.Yamasaki: "Development of 400Vdc Power Distribution System and $400 V d c$ Output Rectifier," Proc. IEEE INTELEC'09, Sess.PA2-1, pp.68-73, Oct. 2009.

[2] U.Badstuebner, J.Biela, J.W.Kolar:” An Optimized, 99\% Efficient, 5kW, Phase-Shift PWM DC-DC Converter for Data Center and Telecom Applications," IPEC'10 Record, pp.626-634, June. 2010.

[3] K.Domoto, et al:" Surge Analysis and Snubber Design for a Full-Bridge Isolated DC-DC Converter in HVDC Power Distribution Systems," IEEJ Trans. IA, Vol.133, No.12, pp.1171-1178, 2013 (in Japanese)

[4] A.Jangwanitlert, J.C.Balda.:'Phase-shifted PWM fullbridge DC-DC converters for automotive applications: reduction of ringing voltages," Proc. IEEE Power Electronics in Transportation, pp.111-115, Oct.2004.

[5] K.Yoshida: "ZVS active clamp full-bridge conveter with CRD snubber circuit," IEICE Technical Report, Vol.101, No.38, pp.43-48,EE2001-5, May 2001 (in Japanese)

[6] K.Orikawa J.Itoh :"Principle of Surge Voltage of a Rectifier in Isolated DC-DC Converters and Snubber Circuit Dsign Method," IEEJ Trans. IA, Vol.133, No.3, pp.350-359, 2013 (in Japanese)

[7] M.Hirokawa, T.Ninomiya : "Non-Dissipative Snubber for Rectifying Diodes in a High-Power DC-DC Converter," IEEJ Trans. IA, Vol.125, No.4, pp.366-371, 2005 (in Japanese).

[8] R.Simanjorang, H.Yamaguchi, H.Ohashi, K.Nakao, T.Ninomiya, S.Abe, M.Kaga, A.Fukui:" High-Efficiency High-Power DC-DC Converter for Energy and Space Saving of Power-Supply System in a Data Center," APEC'11 Record, pp.600-605, Mar. 2011.

[9] H.Kawano (Toyota industries corporation) :"Switching Power Supply circuit,” JPA 2006-230075 (2005.02.16) 
[10] K.Domoto, T.Ninomiya, Y.Ishizuka, S.Abe, M.Kaga, R.Simanjyorang, H.Yamaguchi:"Surge snubber design for high power-density DC-DC converters in HVDC power distribution systems," Proc. IEEE ICRERA'12, pp15,Nov.2012

[11] K. Harada, T. Ninomiya:"On the Mechanism of SwitchingNoise Generarion and its Suppression Techniques in a DCto-DC Converter," IECE Trans. Vol.62, No.12, pp.795802,1979 . 